\title{
ARTICLE \\ Modafinil potentiates cocaine self-administration by a dopamine-independent mechanism: possible involvement of gap junctions
}

\author{
Maddalena Mereu', Takato Hiranita ${ }^{2,4}$, Chloe J. Jordan iD $^{3}$, Lauren E. Chun ${ }^{1}$, Jessica P. Lopez ${ }^{1}$, Mark A. Coggiano ${ }^{1}$, \\ Juliana C. Quarterman ${ }^{1}$, Guo-Hua Bi ${ }^{3}$, Jacqueline D. Keighron ${ }^{1}$, Zheng-Xiong $\mathrm{Xi}^{3}$, Amy Hauck Newman (iD ${ }^{1,3}$, Jonathan L. Katz ${ }^{2}$ and \\ Gianluigi Tanda (iD)
}

\begin{abstract}
Modafinil and methylphenidate are medications that inhibit the neuronal reuptake of dopamine, a mechanism shared with cocaine. Their use as "smart drugs" by healthy subjects poses health concerns and requires investigation. We show that methylphenidate, but not modafinil, maintained intravenous self-administration in Sprague-Dawley rats similar to cocaine. Both modafinil and methylphenidate pretreatments potentiated cocaine self-administration. Cocaine, at self-administered doses, stimulated mesolimbic dopamine levels. This effect was potentiated by methylphenidate, but not by modafinil pretreatments, indicating dopamine-dependent actions for methylphenidate, but not modafinil. Modafinil is known to facilitate electrotonic neuronal coupling by actions on gap junctions. Carbenoxolone, a gap junction inhibitor, antagonized modafinil, but not methylphenidate potentiation of cocaine self-administration. Our results indicate that modafinil shares mechanisms with cocaine and methylphenidate but has a unique pharmacological profile that includes facilitation of electrotonic coupling and lower abuse liability, which may be exploited in future therapeutic drug design for cocaine use disorder.
\end{abstract}

Neuropsychopharmacology (2020) 45:1518-1526; https://doi.org/10.1038/s41386-020-0680-5

\section{INTRODUCTION}

Racemic modafinil (modafinil; Provigil ${ }^{\circledR}$ ) and methylphenidate $\left(\right.$ Ritalin ${ }^{\circledast}$ ) are clinically available for treatment of narcolepsy and attention deficit disorders, respectively. These medications share with cocaine their primary pharmacological target, the blockade of neuronal dopamine (DA) reuptake through the DA transporter (DAT). Indeed, clinically relevant doses of modafinil increase DA levels in the human brain by blocking DAT, similar to therapeutic doses of methylphenidate [1]. These findings support a primary role for DA and DAT in the therapeutic actions of both modafinil [1] and methylphenidate [2].

Actions at DAT have also been implicated in the abuse liability of psychostimulants [3], initially leading to conclusions that drugs that block DAT may have potential for abuse [3]. However, there is evidence that atypical DAT blockers bind with high affinity to DAT, but do not possess cocaine-like reinforcing effects [4]. In this regard, while methylphenidate shares neuro-behavioral activities with cocaine [5], the effects of modafinil differ substantially. In preclinical tests, modafinil and its enantiomers differ from cocaine in their binding at DAT $[6,7]$, which is minimally influenced by DAT conformation. On the other hand, cocaine and methylphenidate have higher DAT affinity when it is in a conformation open as opposed to closed to the extracellular space $[6,7]$. In addition, modafinil and methylphenidate have been evaluated in clinical studies as medications for psychostimulant use disorders, and in the case of modafinil, with some success $[8,9]$. Further, modafinil did not show abuse liability in individuals with cocaine use disorder [10], and to our knowledge, there have been no systematic reports of modafinil abuse, nor identifiable symptoms of withdrawal after its chronic use [11].

Other than stimulating brain DA levels, modafinil has been shown to affect the levels of various neurotransmitters in several brain regions [12] that may play a role in its pharmacological actions. Recent studies have shown that by acting through gap junctions, modafinil plays a facilitative role in electrotonic coupling effects in neuronal and astroglia cells [13, 14]. For instance, modafinil has been proposed to modulate electrical coupling by actions through connexin 30-mediated gap junctions $[14,15]$. Interestingly, in preclinical studies gap junctions have been found to play a role in the effects of modafinil on sleep and cognitive functions $[13,15,16]$, which are impaired in individuals with substance use disorder [17-20]. Furthermore, modafinil

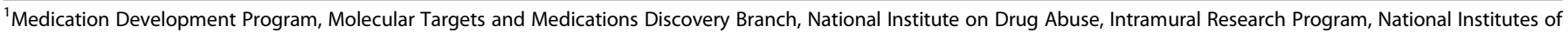

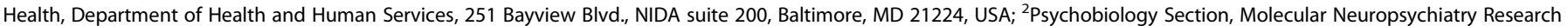

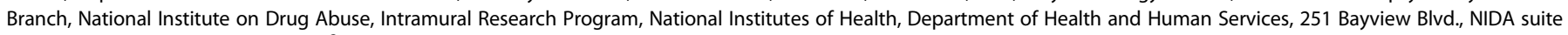

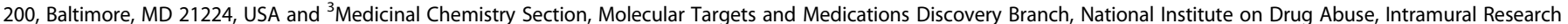
Program, National Institutes of Health, Department of Health and Human Services, 251 Bayview Blvd., NIDA suite 200, Baltimore, MD 21224, USA Correspondence: Gianluigi Tanda (gtanda@mail.nih.gov)

${ }^{4}$ Present address: Department of Pharmacodynamics, College of Pharmacy, University of Florida, 1345 Center Drive, Gainesville, FL 32610, USA These authors contributed equally: Maddalena Mereu, Takato Hiranita, Chloe J. Jordan
}

Received: 5 November 2019 Revised: 15 March 2020 Accepted: 9 April 2020

Published online: 27 April 2020 
treatment has been suggested to attenuate impaired sleep and cognitive functions in psychostimulant addicted subjects [21-23].

Recently, use of modafinil, methylphenidate and other psychostimulants as "smart drugs" to increase intellectual performance among healthy individuals has been debated [24, 25]. Of concern is their use without prescription and their potential for abuse or to facilitate the abuse of other psychostimulants, such as cocaine.

In order to investigate the potential influence of smart drugs like modafinil and methylphenidate on concurrent or subsequent use of illicit substances, we evaluated the following in rats: (1) the reinforcing effects of modafinil compared with methylphenidate using intravenous drug self-administration procedures; (2) the potential of modafinil and methylphenidate to enhance the selfadministration of cocaine; (3) how these findings relate to stimulation of extracellular DA levels measured by in vivo microdialysis with probes implanted in the nucleus accumbens shell (NAS) (Supplementary Fig. S1), a mesolimbic region implicated in the reinforcing effects of drugs [26, 27]; and (4) the potential contribution of facilitation of neuronal electrical coupling through gap junctions [28] to the self-administration of cocaine after pretreatment with modafinil or methylphenidate, by administering carbenoxolone, a gap junction inhibitor, that has been shown to block modafinil's facilitation of electrical coupling, in vitro and in vivo $[13,14,16]$. Notably, carbenoxolone has also shown some behavioral effects dependent on stimulation of DA receptors in striatal areas [29].

\section{MATERIALS AND METHODS}

Subjects

Experimentally naïve, adult, male Sprague-Dawley rats (Taconic Farms, Germantown, NY, or Charles River, Wilmington, MA), 275-350 g, were habituated for at least one week before the start of experiments that were conducted during the light phase of a 12:12-h light-dark cycle (lights on 06:00 a.m.) or for experiments shown in Fig. 5, the dark phase in a reverse light-dark cycle (lights off at 7:00 a.m.). All animals used in the present study were maintained in an AAALAC International accredited facility in accordance with NIH Policy Manual 3040-2, Animal Care and Use in the Intramural Program (released 1 November 1999). The animal research conducted to perform this study was approved by the NIDA-IRP Animal Care and Use Committee, in accordance with the guidelines of the National Institutes of Health.

\section{Compounds}

( \pm )-Modafinil was synthesized [30] in the Medicinal Chemistry Section, NIDA-IRP, and dissolved in a vehicle containing DMSO $10 \%$, Tween $8015 \%$, and saline 75\% (V/V/V). (-)-Cocaine hydrochloride and methylphenidate hydrochloride (SigmaAldrich, St. Louis, MO or NIDA Drug Supply Program) were prepared fresh daily in sterile saline. In some experiments, detailed below, methylphenidate was prepared using the modafinil vehicle. Pretreatment times and doses of drugs used in the present study are described below and were chosen based on preliminary data obtained in this laboratory.

\section{Self-administration studies}

Twelve singly housed subjects were maintained at approximately $320 \mathrm{~g}$ by adjusting daily food rations (Scored Bacon Lover Treats, BIOSERV, Frenchtown, NJ). Water was available at all times in the home cages. During daily experimental sessions, subjects were placed in operant-conditioning chambers (modified ENV-008CT, Med Associates, St. Albans, VT) as described previously [31].

Subjects were initially trained during sessions with food reinforcement (20-mg food pellets, BIOSERV, Frenchtown, NJ) to press the right lever, and were subsequently trained under a fixedratio 5 -response schedule of reinforcement (each fifth response produced a food pellet). Food deliveries were followed by 20-s timeout (TO) periods during which all lights were off, and responses had no scheduled consequences other than a feedback click. These training sessions lasted for 20 min or until 30 food pellets were delivered.

After subjects were responding at a rate at which 30 food pellets were obtained within each of three consecutive sessions, i.v. catheters were surgically implanted in the right or left external jugular vein as described [31].

Cocaine self-administration sessions lasted $2 \mathrm{~h}$ ( $3 \mathrm{~h}$ for carbenoxolone studies) and were conducted until response rates and patterns of responding showed no substantial session-to-session changes (within 25\% deviations for the last three consecutive sessions). During these sessions, the LEDs above the active lever were illuminated when cocaine injections were available. Completion of five responses turned off the LEDs and activated the infusion pump, delivering a unit dose of $1.0 \mathrm{mg} / \mathrm{kg}$. A 20-s TO period, during which LEDs were off, started with the injection. After the TO period, the LEDs were illuminated and responding had scheduled consequences again. Once response rates maintained by cocaine were stable (as above) across sessions, the session was divided into 20-min components, each preceded by a 2-min TO. This arrangement allowed the assessment of different cocaine doses/injection within each component. By adjusting injection volumes and durations, the cocaine dose per injection was incremented in the five sequential components in an ascending order as follows. In the first component, no injection was delivered [which is also referred to as extinction (EXT) because responses had no scheduled consequences other than the feedback click and each fifth response turning off the LEDs for $20 \mathrm{~s}$. The second through fifth components had doses/injection of: $0.03,0.10,0.32$, and $1.0 \mathrm{mg} / \mathrm{kg}$ cocaine. Injection volumes in $\mu \mathrm{l}$ (and durations) for the five components were respectively $0(0 \mathrm{~s})$, $5.6(0.32 \mathrm{~s}), 18.0(1.0 \mathrm{~s}), 56.0(3.2 \mathrm{~s})$, and $180(10 \mathrm{~s})$, based on a body weight of $0.32 \mathrm{~kg}$. A response-independent "sample" injection of cocaine at the corresponding dose was administered immediately before each component.

Training continued until stability was obtained, which consisted of: (1) at least $5.0 \mathrm{mg} / \mathrm{kg}$ of cocaine was self-administered within a session with $<20 \%$ variation in the total number of cocaine injections compared with the previous session; (2) the dose of cocaine that maintained maximal response rates varied by no more than one-half log unit over two consecutive test sessions; and (3) maximum response rates were at least twofold higher than response rates maintained during EXT. This criterion was subsequently used for the remainder of the study.

When performances were stable across successive sessions, the effects of presession intraperitoneal (i.p.) injections of methylphenidate or $( \pm)$-modafinil on response rates maintained by cocaine injections were assessed, with and without carbenoxolone pretreatment. Presession treatments were separated by a minimum of $72 \mathrm{~h}$ and were conducted only if performances met the training criteria. All tests were conducted with a mixed order of drugs and doses.

Response rates were determined by dividing responses by elapsed time in each component, excluding the TOs that followed drug injections. A one-way, or two-way, repeated measures ANOVA was used to assess the effects of self-administered dose of cocaine, saline, $( \pm$ )-modafinil, or methylphenidate (successive components) as appropriate, with a post-hoc Bonferroni $t$-test used for pairwise comparisons. For the experiments with methylphenidate, the modafinil vehicle was used.

In vivo brain microdialysis

Probes had an active dialyzing surface of $1.8-2.0 \mathrm{~mm}$, and were implanted during surgical procedures [uncorrected coordinates: [32] anterior $=+2.0 \mathrm{~mm}$, and lateral $= \pm 1.0 \mathrm{~mm}$ from bregma; vertical $=-7.9 \mathrm{~mm}$ from dura (see Supplementary Fig. S1 for 

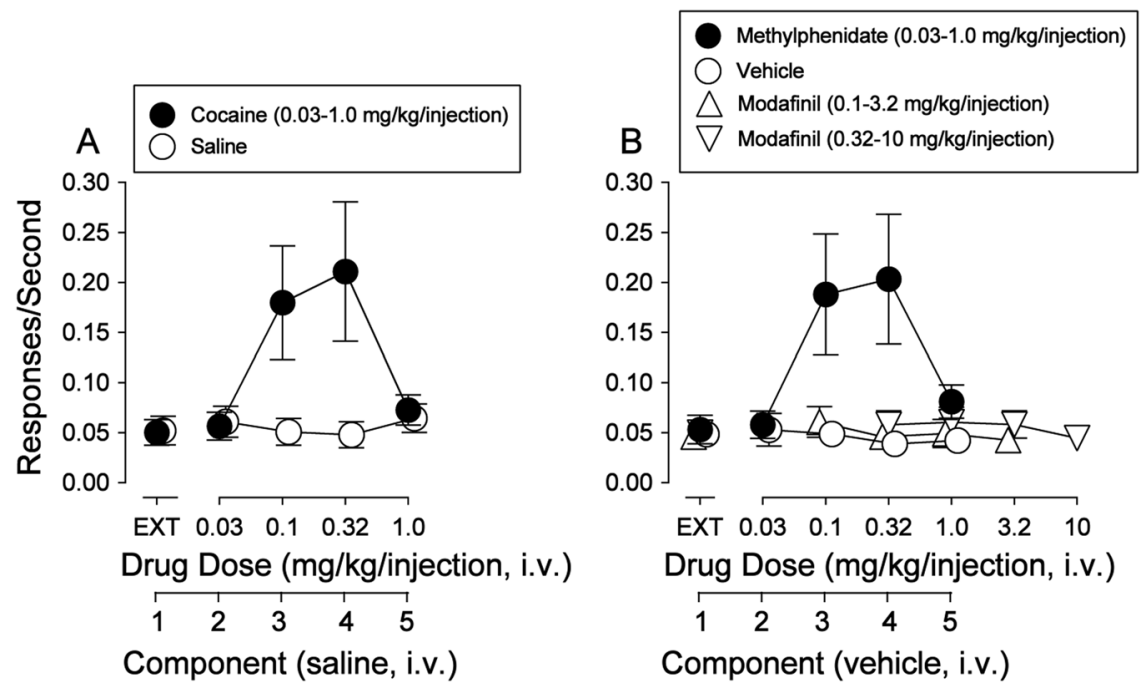

Fig. 1 Methylphenidate, but not modafinil, sustains self-administration behavior. Effects of substitution of saline, vehicle for modafinil, modafinil (lower and higher ranges of the doses), or the standard DA uptake inhibitor methylphenidate (dissolved in the modafinil vehicle), in rats trained to self-administer cocaine. Ordinates, responses per second; abscissae, dose of each drug in milligrams per kilogram per injection or saline or modafinil vehicle sequential component of the session. Each point represents the mean, with vertical bars representing S.E.M. $(n=6)$. a cocaine and saline. b vehicle, methylphenidate, modafinil (0.1-3.2 mg/kg/inj) and modafinil (0.32-10 mg/kg/inj). EXT extinction.

probe placements)] under a mixture of ketamine and xylazine anesthesia, 60.0 and $12.0 \mathrm{mg} / \mathrm{kg}$ i.p., respectively, as described [5]. During the same surgical procedure, a silastic catheter was implanted into the right external jugular vein as previously described [33]. Experiments were performed on freely moving subjects, $\sim 22-24 \mathrm{~h}$ after probe implantation. Dialysates were sampled every $10 \mathrm{~min}$ and immediately analyzed. After reaching stable DA values (2-4 consecutive samples, $<15 \%$ variability), subjects were treated with drugs. Subjects were injected during a single microdialysis session with i.v. injections of vehicle, modafinil $(10,17,32$, and $56 \mathrm{mg} / \mathrm{kg})$, methylphenidate $(0.1,0.3,1.0$, and 3.0 $\mathrm{mg} / \mathrm{kg})$, or cocaine $(0.03,0.1,0.3$, and $1.0 \mathrm{mg} / \mathrm{kg})$, spaced $30 \mathrm{~min}$ apart [34]. Modafinil (10, 17, or $32 \mathrm{mg} / \mathrm{kg}$, i.p.), or methylphenidate (1 or $3.2 \mathrm{mg} / \mathrm{kg}$, i.p.) pretreatments were administered to different groups of subjects $10 \mathrm{~min}$ before receiving cocaine, $0.03,0.1,0.3$, and $1.0 \mathrm{mg} / \mathrm{kg}$, i.v., or saline injections, spaced $30 \mathrm{~min}$ apart.

DA was detected by HPLC coupled with a coulometric detector (5200a Coulochem II, or Coulochem III, ESA, Chelmsford, MA, USA) as described [5]. Assay sensitivity for DA was 2 fmoles per sample. Data were used only from subjects for which probe tracks were within the correct NAS boundaries, confirmed by histology, as described [5] (Supplementary Fig. S1).

Microdialysis results were expressed as a percentage of basal DA values. Statistical analysis was carried out using one- or twoway ANOVA (factors: time, drug dose, or drug pretreatment) for repeated measures over time with significant results subjected to post-hoc Tukey's test. The average basal DA values in dialysates in the present experiments were $39.5 \pm 6.6 \mathrm{fmoles}( \pm$ S.E.M.) in a $10 \mu \mathrm{l}$ sample, $n=90$. No significant differences $(p>0.05)$ were found in basal DA concentrations across all the experimental groups (ANOVA, $F_{14,75}=1.11, p=0.364$ ).

\section{RESULTS}

Methylphenidate, but not modafinil, sustains intravenous self-administration

Average response rates maintained by cocaine were a bell-shaped function of injection dose, with a $0.211 \pm 0.070$ responses/s maximum at $0.32 \mathrm{mg} / \mathrm{kg} / \mathrm{injection}$. The maximum response rate was more than four-fold higher and significantly greater than the $0.050 \pm 0.013$ responses/s occurring in EXT (Fig. 1a, filled circles above EXT). A two-way repeated measures ANOVA indicated a significant difference in response rates vs. vehicle indicative of reinforcing effects of cocaine $\left(F_{1,20}=8.81, p=0.031\right.$; post-hoc, 0.1 and $0.32 \mathrm{mg} / \mathrm{kg} /$ injection vs. EXT, $t$ values $\geq 4.57, p$ values $\leq 0.001$ ). Neither saline nor the vehicle used for modafinil maintained response rates substantially greater than those obtained in EXT (Fig. 1a, b, open circles).

As with its vehicle, modafinil (0.1-3.2 $\mathrm{mg} / \mathrm{kg} /$ injection) did not maintain rates of responding appreciably greater than those obtained in EXT (Fig. 1b, open triangles up; $F$ values $\leq 2.14$; $p$ values $\geq 0.114)$. When a higher range of modafinil doses was studied $(0.32-10 \mathrm{mg} / \mathrm{kg} / \mathrm{inj})$, a largely similar outcome was obtained (Fig. 1b, open triangles down). However, modafinil at the dose of $3.2 \mathrm{mg} / \mathrm{kg} /$ injection on this occasion produced a slight increase of 0.019 responses/s (approximately 12-fold lower than the increase produced by $0.32 \mathrm{mg} / \mathrm{kg} /$ injection cocaine). A twoway repeated measures ANOVA was significant $\left(F_{1,20}=8.61, p=\right.$ 0.032 ), but did not result in any significant difference in the number of modafinil infusions compared with vehicle infusions (main effect treatment $F_{2,10}=1,624, p=0.245$ ).

Like cocaine, methylphenidate maintained rates of responding substantially greater than those obtained in EXT (Fig. 1b, filled circles). A two-way repeated measures ANOVA for response rates yielded significant differences from vehicle self-administration, indicative of reinforcing effects (response rates, $F_{1,20}=8.84 ; p=$ 0.031 ; component/dose, $F_{4,20}=7.01 ; p=0.001$; and their interaction, $F_{4,20}=6.52 ; p=0.002 ;$ post-hoc, 0.1 and $0.32 \mathrm{mg} / \mathrm{kg} /$ injection vs. vehicle, $t$ values $\geq 3.90, p$ values $\leq 0.001$ ).

Modafinil and methylphenidate potentiate cocaine self-administration

Presession treatments with modafinil dose-dependently shifted the cocaine self-administration dose-effect curve to the left (Fig. 2a), indicating a potentiation of cocaine self-administration. A two-way repeated measures ANOVA yielded significant effects of cocaine dose $\left(F_{4,60}=7.90, p<0.001\right)$, presession treatment dose of modafinil $\left(F_{3,60}=8.83, p<0.001\right)$, and a significant interaction of the two $\left(F_{12,60}=6.56, p<0.001\right)$. The lowest dose of modafinil, $10 \mathrm{mg} / \mathrm{kg}$, was inactive, while doses of 17 and $32 \mathrm{mg} / \mathrm{kg}$ left-shifted the dose-effect curve $\sim 3$ - and 10-fold, respectively (Fig. 2a). Post-hoc comparisons indicated that pretreatment with modafinil (17 or $32 \mathrm{mg} / \mathrm{kg}$ ) significantly increased response rates compared with vehicle pretreatment 


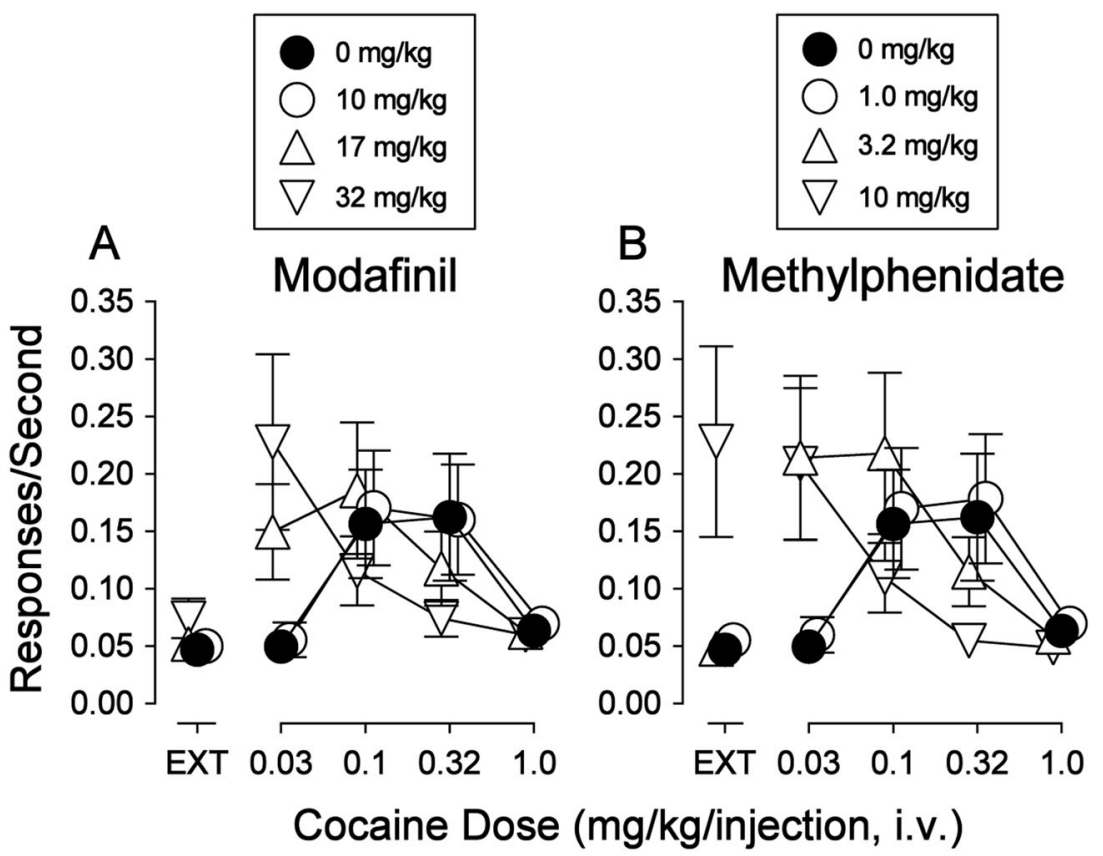

Fig. 2 Methylphenidate and modafinil potentiate cocaine self-administration. Effects of presession treatments with modafinil and methylphenidate on responding maintained by cocaine injections. Ordinates: Responses per sec. Abscissae: Cocaine injection dose in milligrams per kilogram per injection. Each point represents the mean, with vertical bars representing S.E.M. ( $n=6$ ). Modafinil and methylphenidate both were administered i.p. at $5 \mathrm{~min}$ before sessions. a Effects of modafinil (10, 17 and $32 \mathrm{mg} / \mathrm{kg}$, i.v.) on cocaine selfadministration. b Effects of methylphenidate $(1.0,3.2$, and $10 \mathrm{mg} / \mathrm{kg}$, i.v.) on cocaine self-administration. The vehicle consists of distilled water including 10\% DMSO and 15\% Tween 80 . EXT extinction.

at the $0.032 \mathrm{mg} / \mathrm{kg} /$ injection dose of cocaine $(t \geq 4.06, p<0.001)$. In addition, the highest dose $(32 \mathrm{mg} / \mathrm{kg}$ ) of modafinil significantly decreased response rates compared with vehicle pretreatment at $0.32 \mathrm{mg} / \mathrm{kg} / \mathrm{injection}$ of cocaine $(t=3.59, p=0.004)$.

Presession treatments with methylphenidate also left-shifted the cocaine self-administration dose-effect curve (Fig. 2b). A twoway repeated measures ANOVA indicated significant effects of cocaine dose $\left(F_{4,60}=6.56, p<0.01\right)$, pre-session treatment dose of methylphenidate $\left(F_{3,60}=6.91, p<0.01\right)$, and an interaction of the two $\left(F_{12,60}=6.57, p<0.01\right)$. These effects were dose related. The lowest dose, $1.0 \mathrm{mg} / \mathrm{kg}$, was inactive, while doses of 3.2 and 10 $\mathrm{mg} / \mathrm{kg}$ left-shifted the cocaine dose-effect curve approximately $\sim 3-$ and 10-fold, respectively (Fig. 2b). Post-hoc comparisons indicated significantly increased response rates with methylphenidate $(3.2$ or $10 \mathrm{mg} / \mathrm{kg}$ ) vs. saline pretreatment at the $0.032 \mathrm{mg} /$ $\mathrm{kg} /$ injection dose of cocaine $(t \geq 4.43, p<0.001)$. In addition, the highest dose of methylphenidate, $10 \mathrm{mg} / \mathrm{kg}$, significantly decreased response rates compared with saline pretreatment at $0.32 \mathrm{mg} / \mathrm{kg} / \mathrm{injection}$ of cocaine $(t=2.99, p<0.05)$. Further, that dose of methylphenidate also increased response rates during EXT (Fig. 2b, downward triangles above EXT; $t=5.04, p<0.001$ ).

Effects of modafinil and methylphenidate on extracellular NAS DA levels

Modafinil, $10-56 \mathrm{mg} / \mathrm{kg}$, i.v. or methylphenidate, $0.1-3.0 \mathrm{mg} / \mathrm{kg}$, i.v., administered at $30 \mathrm{~min}$ intervals, significantly stimulated extracellular NAS DA levels (Fig. 3a, b). Two-way repeated measures ANOVA indicated significant main effects of modafinil dose $\left(F_{4,44}=6.44, p<0.001\right)$ and time $\left(F_{2,88}=5.55, p<0.01\right)$, and a non-significant interaction of the two $\left(F_{8,88}=0.79, p>0.05\right)$, and indicated also significant effects of methylphenidate dose $\left(F_{4,20}=\right.$ $18.0, p<0.0001)$, time $\left(F_{2,40}=21.2, p<0.0001\right)$, and their interaction $\left(F_{8,40}=4.42, p<0.05\right)$. No significant changes were obtained with i.v. injections of modafinil vehicle or saline $(p>0.05)$.

A comparison of the maximum stimulation of DA levels produced by i.v. modafinil, $10-56 \mathrm{mg} / \mathrm{kg}$, methylphenidate,
$0.1-3.0 \mathrm{mg} / \mathrm{kg}$, or cocaine, $0.03-3.0 \mathrm{mg} / \mathrm{kg}$, is shown in Fig. 3c. Cocaine and methylphenidate were equipotent and equi-effective in stimulating extracellular DA in the NAS, whereas modafinil had approximately 100 -fold lower potency, and was also substantially less effective in stimulating DA levels than cocaine or methylphenidate, at nontoxic doses. Nonetheless, doses of cocaine and methylphenidate that maintained response rates significantly greater than vehicle, i.e., $0.1 \mathrm{mg} / \mathrm{kg}$ (Fig. 1), produced a stimulation of DA to $\sim 157 \%$ of basal levels (indicated by the dashed line on Fig. 3c). Each dose of modafinil studied produced increases in DA concentration greater than those produced by self-administered doses of cocaine or methylphenidate. The lowest tested dose of modafinil $(10 \mathrm{mg} / \mathrm{kg}$, i.v.), which was not self-administered, produced an increase in DA that was $\sim 164 \%$ of basal levels (above the dashed line on Fig. 3c).

The maximal increases in DA concentrations obtained with modafinil were about $250 \%$ of basal levels compared with $\sim 700 \%$ or $\sim 800 \%$ increases in DA levels obtained with cocaine or methylphenidate, respectively (Fig. 3c). The highest dose of modafinil $(56 \mathrm{mg} / \mathrm{kg}$, i.v.) also produced acute toxicity with convulsions in two of six subjects, whereas increases produced by the highest doses of cocaine or methylphenidate were obtained without any grossly observable convulsant or proconvulsant effects.

Methylphenidate, but not modafinil, potentiates cocaine-enhanced stimulation of NAS DA

Pretreatments with modafinil, $10-32 \mathrm{mg} / \mathrm{kg}$ i.p., had no significant effect on cocaine-induced stimulation of NAS DA (Fig. 4a and Supplementary Fig. S2). In contrast, pretreatments with methylphenidate (1.0 or $3.2 \mathrm{mg} / \mathrm{kg}$, i.p., $10 \mathrm{~min}$ prior to cocaine) enhanced the stimulation of DA levels produced by i.v. cocaine (Fig. 4b and Supplementary Fig. S2). A two-way repeated measures ANOVA indicated significant main effects of dose $\left(F_{2,9}\right.$ $=7.79, p<0.02)$, time $\left(F_{14,126}=14.03, p<0.0001\right)$, and dose by time interaction $\left(F_{28,126}=1.72, p<0.05\right)$. 

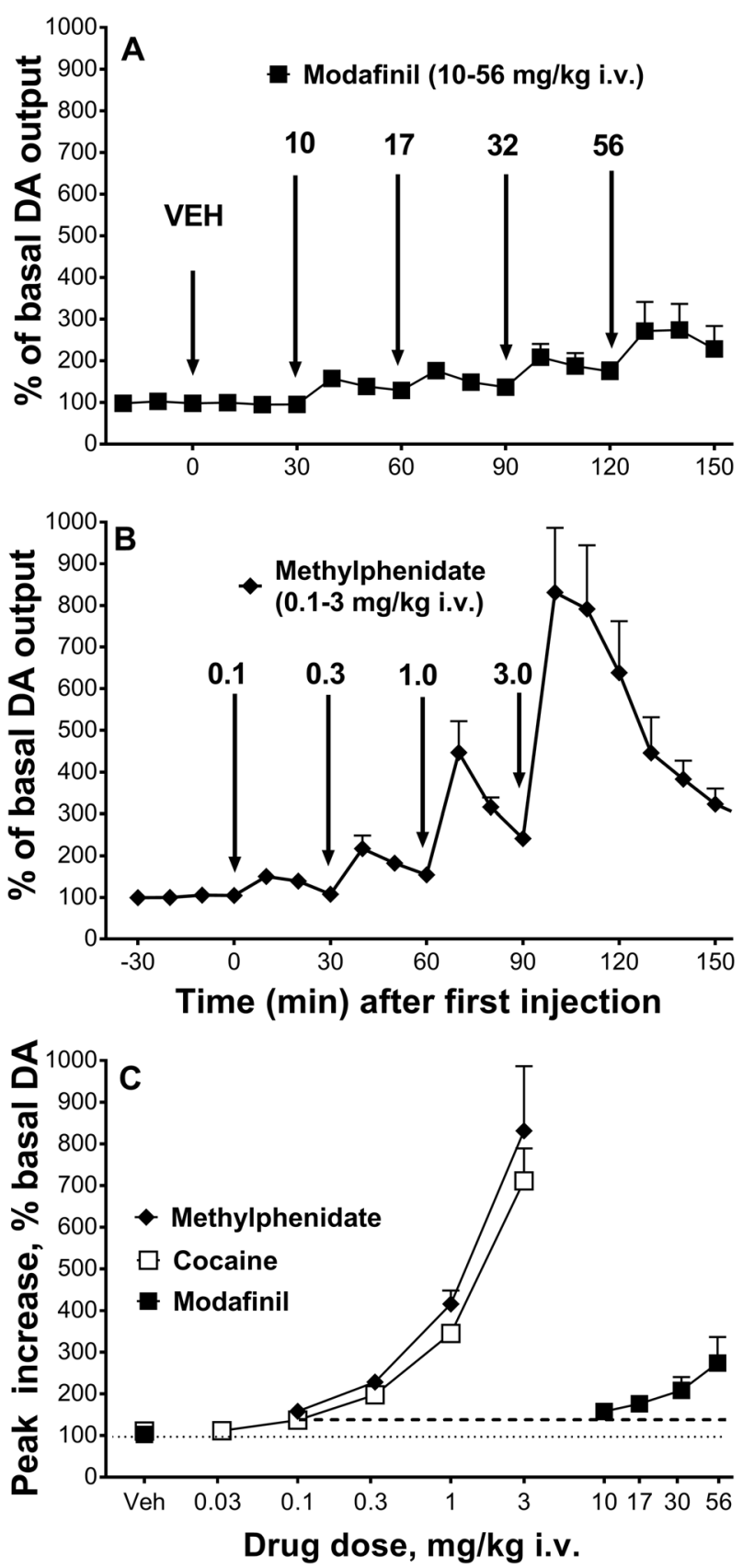

Fig. 3 Different stimulation of accumbens DA levels by methylphenidate and modafinil. Effects of i.v. administration of selected modafinil, methylphenidate, or cocaine doses spaced $30 \mathrm{~min}$ apart on stimulation of extracellular DA levels in dialysates from rats in which a microdialysis probe was implanted in the NAS. Results are means, with vertical bars representing S.E.M. $(n=6)$, of the amount of DA in 10-min dialysate samples, expressed as percentages of basal values. a Time course of modafinil administration (10-56 mg/ $\mathrm{kg}$, i.v.). b Time course of methylphenidate administration (0.1-3.0 $\mathrm{mg} / \mathrm{kg}$, i.v.). c Comparison of effects of various doses of modafinil, methylphenidate, and cocaine on maximal increases in extracellular DA levels in dialysates from the NAS. The dotted line indicates DA baseline $(100 \%)$, whereas the dashed line indicates the maximal increase over basal DA values obtained with the lowest selfadministered doses of cocaine or methylphenidate. Note that, the modafinil dose of $10 \mathrm{mg} / \mathrm{kg}$ i.v. elicited an increase in DA levels comparable to the lowest self-administered doses of cocaine and methylphenidate; however, modafinil did not maintain selfadministration behavior above vehicle levels.
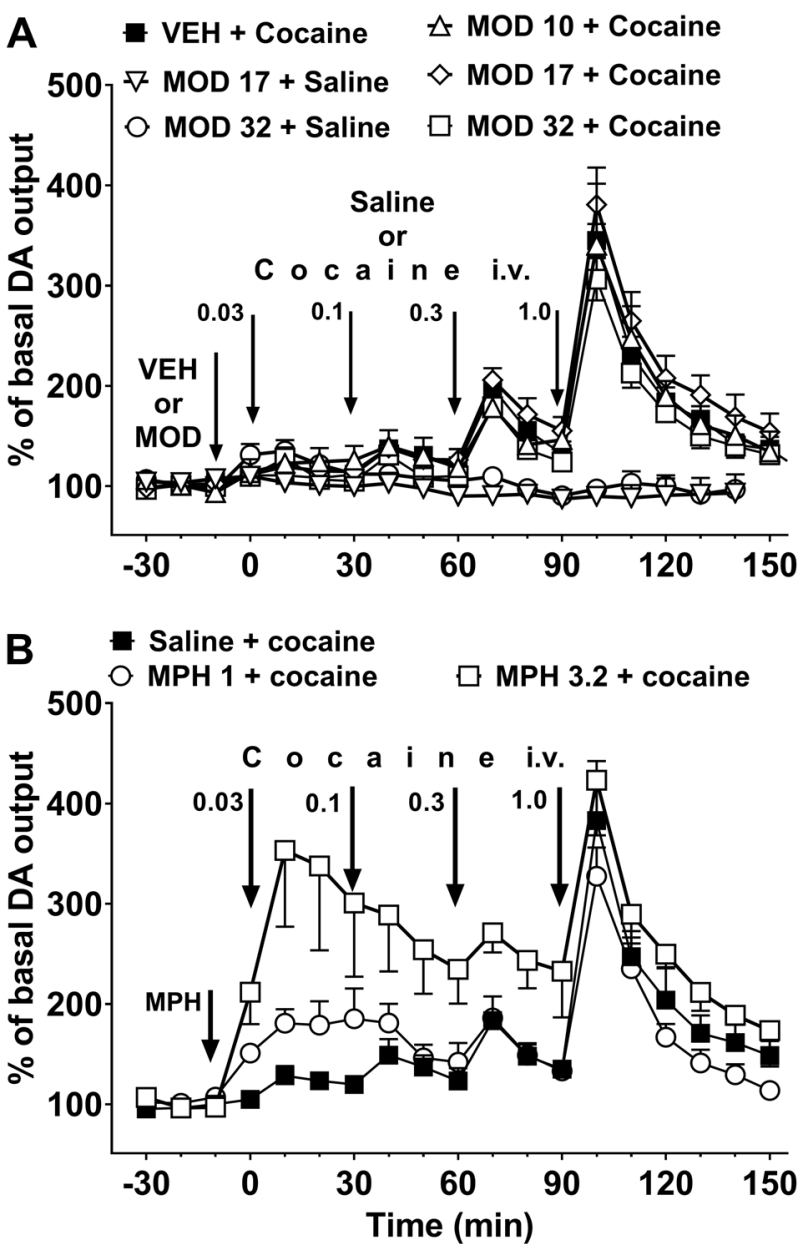

Fig. 4 Methylphenidate, but not modafinil, potentiates cocaineinduced stimulation of DA levels. Effects of a modafinil (10-32 mg/ $\mathrm{kg}$, i.p.) or $\mathbf{b}$ methylphenidate (1.0 and $3.2 \mathrm{mg} / \mathrm{kg}$, i.p.) pretreatments on cocaine-induced stimulation of DA levels from NAS dialysates at cocaine doses $(0.03-1.0 \mathrm{mg} / \mathrm{kg}$, i.v.) that maintain self-administration behavior. Results are means, with vertical bars representing S.E.M. $(n=4-7)$, of the amount of DA in 10-min dialysate samples, expressed as percentage of basal values. VEH vehicle, MOD modafinil, MPH methylphenidate.

The enhancement produced by 1.0 or $3.2 \mathrm{mg} / \mathrm{kg}$ of methylphenidate dissipated by, respectively, $\sim 30$ or $\sim 90$ min after injection, corresponding to the time course of effects of methylphenidate administered alone (see Supplementary Fig. S2). There was no significant alteration in the dopaminergic effects of the highest dose of cocaine (Fig. 4b), which was administered about $90 \mathrm{~min}$ after methylphenidate. In a separate experiment (Supplementary Fig. S2), methylphenidate (3.2 mg/kg, i.p.), but not modafinil (17 $\mathrm{mg} / \mathrm{kg}$, i.p.), administered $10 \mathrm{~min}$ before the highest cocaine dose $(1.0 \mathrm{mg} / \mathrm{kg}$, i.v.) enhanced the stimulation of DA levels induced by cocaine $(1.0 \mathrm{mg} / \mathrm{kg}$, i.v., Supplementary Fig. S2).

Blockade of gap junctions by carbenoxolone attenuates modafinil- but not methylphenidate-induced potentiation in cocaine self-administration behavior

The differences in outcomes between methylphenidate and modafinil in combination with cocaine on NAS DA levels suggests a difference in the mechanisms of action of these two drugs beyond DAT inhibition. Since modafinil, but not methylphenidate, has been implicated in mediating neuronal electrical coupling via 

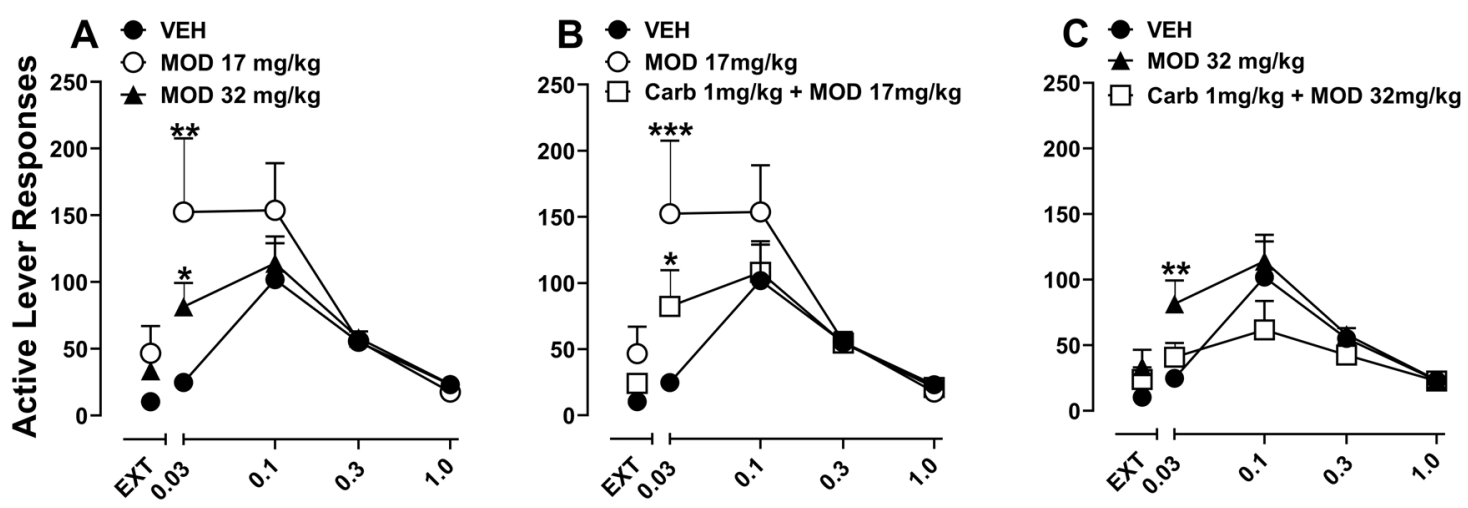

\section{Cocaine Dose (mg/kg/injection, i.v.)}
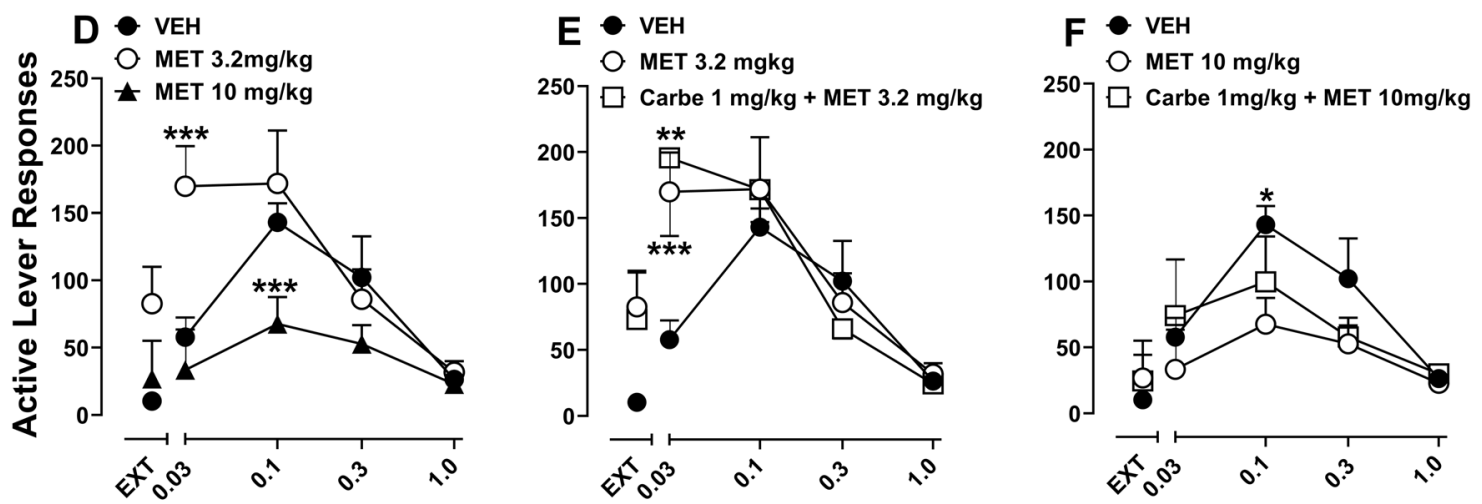

\section{Cocaine Dose (mg/kg/injection, i.v.)}

Fig. 5 Inhibition of gap junctions antagonizes modafinil, but not methylphenidate potentiation of cocaine self-administration. Effects of carbenoxolone, a gap junction inhibitor, on modafinil- vs. methylphenidate-induced potentiation of cocaine self-administration. Ordinates: Active lever responses. Abscissae: Cocaine injection dose in milligrams per kilogram per injection. Each point represents the mean, with vertical bars representing S.E.M. $(n=6-10)$. Modafinil or methylphenidate with or without carbenoxolone $(1.0 \mathrm{mg} / \mathrm{kg}$, i.p., $5 \mathrm{~min}$ prior to each session) was administered i.p. at 5 min before sessions. a Replicated effects of modafinil (MOD, 17 and $32 \mathrm{mg} / \mathrm{kg} ; n=6$ and 10 , respectively) on cocaine self-administration (Vehicle, VEH, $n=9$ ). b Effects of the lower dose of modafinil $(17 \mathrm{mg} / \mathrm{kg})$ in the presence or absence of carbenoxolone (Carben, $1 \mathrm{mg} / \mathrm{kg}$ i.p., $n=10$ ) on cocaine self-administration. c Effects of the higher dose of modafinil $(32 \mathrm{mg} / \mathrm{kg})$ in the presence or absence of carbenoxolone $(1 \mathrm{mg} / \mathrm{kg}$ i.p., $n=8)$ on cocaine self-administration. $\mathbf{d}$ Replicated effects of methylphenidate (MET, 3.2 and $10 \mathrm{mg} / \mathrm{kg} ; n=8$ and 8 , respectively) on cocaine self-administration (Vehicle, VEH, $n=8$ ). e Effects of the lower dose of methylphenidate $(3.2 \mathrm{mg} / \mathrm{kg})$ in the presence or absence of carbenoxolone $(1 \mathrm{mg} / \mathrm{kg}$ i.p., $n=8)$ on cocaine self-administration. $f$ Effects of the higher dose of methylphenidate $(10 \mathrm{mg} / \mathrm{kg})$ in the presence or absence of carbenoxolone $(1 \mathrm{mg} / \mathrm{kg}$ i.p., $n=10)$ on cocaine self-administration. The vehicle consists of distilled water including $10 \%$ DMSO and $15 \%$ Tween 80 . EXT: extinction. ${ }^{*} p<0.05,{ }^{* *} p<0.01,{ }^{* * *} p<0.001$ vs. vehicle.

actions at gap junctions, we next compared the effects of modafinil and methylphenidate on cocaine self-administration after pretreatments with the gap junction inhibitor, carbenoxolone [13], in other groups of subjects. As before, pretreatment with modafinil produced significant leftward shifts in the cocaine self-administration dose-effect curve (Fig. 5a), two-way ANOVA dose by treatment interaction, $F_{8,135}=2.86, p<0.006$. Post-hoc testing revealed that both 17 and $32 \mathrm{mg} / \mathrm{kg}$ modafinil increased self-administration of $0.03 \mathrm{mg} / \mathrm{kg} /$ injection of cocaine $(p<0.02)$.

Carbenoxolone pretreatment, $1.0 \mathrm{mg} / \mathrm{kg}$ i.p., significantly reduced the enhancement of cocaine self-administration behavior produced by $17 \mathrm{mg} / \mathrm{kg}$ of modafinil (Fig. 5b). A two-way ANOVA indicated a dose by treatment interaction $\left(F_{8,135}=2.42, p<0.01\right)$. At $32 \mathrm{mg} / \mathrm{kg}$ of modafinil (Fig. 5c), the two-way ANOVA dose by treatment interaction was not significant $\left(F_{8,159}=1.7, p=0.1\right)$. However, post-hoc analyses indicated that rates of response at $0.03 \mathrm{mg} / \mathrm{kg} /$ injection of cocaine were significantly increased by modafinil alone compared with vehicle $(p<0.01)$. In contrast, when modafinil was administered with carbenoxolone responding did not differ from vehicle treatment. Carbenoxolone alone did not significantly alter cocaine self-administration, two-way
ANOVA, main effect treatment, $F_{1,4}=1.643, p=0.2$; dose by treatment interaction, $F_{4,104}=2.3, \quad p=0.06 \quad$ (Supplementary Fig. S3).

In contrast to modafinil (Fig. 5b, c), pretreatments with carbenoxolone did not alter methylphenidate-induced enhancement of cocaine self-administration (Fig. 5e, f). As before, pretreatment with methylphenidate produced significant increases in the rate of active lever pressing maintained by cocaine injection (Fig. 5d). A two-way ANOVA indicated a dose by treatment interaction $\left(F_{8,129}=2.8, p<0.006\right)$. Post-hoc testing indicated that $3.2 \mathrm{mg} / \mathrm{kg}$ methylphenidate increased self-administration responding both under EXT conditions $(p<0.02)$, as well as at $0.03 \mathrm{mg} / \mathrm{kg} /$ injection cocaine $(p<0.001)$. In addition, $10 \mathrm{mg} / \mathrm{kg}$ methylphenidate significantly decreased responding maintained by $0.1 \mathrm{mg} / \mathrm{kg} /$ injection cocaine $(p=0.002)$. Administration of carbenoxolone prior to methylphenidate pretreatment did not significantly alter effects of either dose of methylphenidate on cocaine selfadministration (Fig. 5e, f), two-way ANOVA dose by treatment interaction for $3.2 \mathrm{mg} / \mathrm{kg}$ methylphenidate $\left(F_{8,123}=2.45, p<0.02\right)$, but no significant post-hoc tests; for $10 \mathrm{mg} / \mathrm{kg}$ methylphenidate $\left(F_{8,147}=1.18, p=0.30\right)$. 


\section{DISCUSSION}

The present study provides a series of novel and unexpected findings about modafinil and its interactions with cocaine. First, modafinil was not self-administered, even at i.v. doses that increased extracellular NAS DA to levels greater than those elicited by self-administered doses of methylphenidate or cocaine. Second, both modafinil and methylphenidate potentiated the reinforcing effects of cocaine, but at variance with methylphenidate, modafinil did not enhance cocaine-induced stimulation of extracellular DA levels, suggesting a unique mechanism by which modafinil interacts with cocaine unrelated to DAT. Finally, potentiation of cocaine's reinforcing effects by modafinil, but not by methylphenidate, was attenuated by the gap junction blocker, carbenoxolone. Importantly, under these same experimental conditions, carbenoxolone when administered alone did not significantly modify cocaine self-administration.

These findings suggest that modafinil potentiates the selfadministration of cocaine through facilitation of electrotonic coupling, a mechanism that has received little attention in the addiction field (see for example: $[29,35,36])$. Our results show that substantial differences exist between modafinil and methylphenidate in terms of abuse potential. As expected, and unlike modafinil, methylphenidate maintained self-administration behavior and significantly increased NAS DA levels at doses comparable to those of cocaine, as described for other species and human subjects $[37,38]$.

Under our experimental conditions, modafinil when substituted for cocaine, did not maintain self-administration above vehicle levels, even at a dose $(10 \mathrm{mg} / \mathrm{kg}$, i.v. $)$ that stimulated extracellular NAS DA to levels greater than those obtained by administration of the doses of cocaine or methylphenidate $(0.1 \mathrm{mg} / \mathrm{kg}$ i.v.) that were self-administered. This result is consistent with the absence of reports on abuse of modafinil in humans [39]. In our study, both modafinil and methylphenidate pretreatments potentiated the reinforcing effects of cocaine. Such effects, if translatable to human subjects, suggest a potential facilitation of cocaine abuse. However, to our knowledge, consistent reports of concurrent use or abuse of modafinil and psychostimulants have not appeared, and modafinil has been shown to reduce cocaine use in selected populations of cocaine abusers [40,41].

Administration of methylphenidate at doses that potentiated cocaine self-administration also enhanced the effects of cocaine on NAS DA dialysates. Unexpectedly, when modafinil was injected in combination with cocaine at doses that potentiated cocaine self-administration, there was no enhancement of cocaineinduced stimulation of DA levels. The lack of potentiation of the dopaminergic effects of cocaine by modafinil suggests that a pharmacokinetic interaction did not underly the modafinil potentiation of cocaine self-administration, as that type of interaction would be expected to also alter the effects of cocaine on NAS DA levels. It is of interest to note that in our experiments methylphenidate was approximately five-fold more potent than modafinil in potentiating cocaine self-administration, despite methylphenidate having $\sim 100$-fold greater affinity than modafinil for DAT binding [7] and, importantly, for in vivo stimulation of NAS DA levels (present results). These differences in potency suggest that the effects of the two drugs on cocaine self-administration might be due to mechanisms other than those mediated by DAT.

Recent evidence suggests that some actions of modafinil may be mediated by facilitation of electrotonic coupling via effects at gap junctions [13]. In the present study, the gap junction inhibitor, carbenoxolone, selectively reduced the potentiation of cocaine self-administration produced by nontoxic doses of modafinil, but not by methylphenidate. Specifically, carbenoxolone attenuated the potentiation of cocaine self-administration by the $17 \mathrm{mg} / \mathrm{kg}$ modafinil dose, and less so at the $32 \mathrm{mg} / \mathrm{kg}$ modafinil dose. The attenuation of modafinil's effects by carbenoxolone could be due to enhancement of cocaine self-administration by carbenoxolone alone. However, there was only a modest and non-significant increase in cocaine self-administration when carbenoxolone was administered in the absence of modafinil. Thus, the data collected to date suggest that the potentiation of the self-administration of cocaine by the low, nontoxic modafinil dose is a result of a facilitation of electrotonic coupling which may in turn indirectly enhance the dopaminergic postsynaptic signal elicited by cocaine administration [29, 35] or neuronal ensembles in the NAS [42]. Indeed, it has been shown that both systemic and ventral striatal administration of carbenoxolone selectively blocked oral stereotypies induced by administration of the dopamine agonist, apomorphine [29]. Thus, a facilitation of electrotonic coupling might play a role in specific behaviors mediated by activation of dopamine receptors. The present study is limited by the testing of only one gap junction inhibitor, carbenoxolone, for its effects on the response to modafinil. However, previous studies have shown that the effectiveness of this drug to alter different in vivo and in vitro actions of modafinil has been replicated with administration of other gap junction inhibitors $[13,14,16]$. Those results suggest that carbenoxolone can serve as an initial indicator for assessing the facilitatory effects of modafinil on gap junctions.

The lower potency of modafinil to increase DA levels was accompanied by a limited efficacy (maximal increase of $250 \%$ ) as compared with cocaine or methylphenidate $(>700 \%$ of basal values for both drugs), at doses that did not elicit acute toxicity. Such low potency and efficacy in the maximal stimulation of DA levels produced by modafinil might also have an impact on its lower reinforcing efficacy assessed by self-administration procedures. Indeed, even after delivery of multiple doses and accumulation of a substantial cumulative dose of modafinil, the dialysis data suggest that DA levels would still be substantially low. This contrasts with the effects of cocaine and methylphenidate that show a steeper dose-dependent increase in DA levels, which may facilitate their self-administration as compared with that with modafinil. The present effects are consistent with previous results in mice, in which a modafinil dose-effect curve, at doses devoid of acute toxic effects, showed limited efficacy, a more shallow slope, and clear evidence of a plateau in maximal DA stimulation $[6,43,44]$. Thus, this apparent lower efficacy of modafinil in stimulating DA levels may also play a role in its limited, if any, abuse liability.

In line with differences between modafinil and other psychostimulants, high doses of methylphenidate increased rates of responding during the EXT component prior to cocaine selfadministration, an effect often referred to as reinstatement. In contrast, modafinil showed no tendency to produce a similar effect in the present and previous [45] studies, and could actually block cocaine or opioid reinstatement, effects possibly mediated by changes in glutamate levels [12]. These reports suggest critical differences in modafinil actions compared with those of the standard psychomotor stimulant profile, which our data suggest may be due in part to effects at gap junctions. However, an increase in previously extinguished responding was reported [46] in nonhuman primates following modafinil treatment, and an increase in time spent in a compartment previously associated with cocaine effects was obtained in rodents [47]. These and the present findings with modafinil suggest a limited effectiveness to promote relapse to drug use. Similar outcomes were reported for $\mathrm{N}$-substituted analogs of benztropine [31] which also blunt psychomotor stimulant effects [4].

Recent clinical studies report positive therapeutic outcomes in a subpopulation of patients with modafinil, but not methylphenidate [8] treatment in cocaine-dependent individuals [40, 41]. Differences in beneficial effects of these drugs could be related to their different interaction with the dopaminergic system and with facilitation of electrotonic coupling. This latter effect has been suggested to play a role in the therapeutic effects of modafinil on sleep disorders and cognitive function $[13,15,16]$, which are also 
impaired in subjects with substance use disorder $[12,20]$. Moreover, modafinil has been reported to improve sleep and cognitive function in psychostimulant-dependent subjects [12, 22, 48, 49]. Thus, though the present study did not directly address how facilitation of gap junction effects of modafinil might be linked to its therapeutic efficacy, it suggests important differences from methylphenidate related to its use as medication for substance use disorder. These results indicated a limited, if any, abuse potential for modafinil, in agreement with the lack of systematic reports of modafinil abuse in humans $[12,39]$. Moreover, lack of potentiation of the dopaminergic effects of cocaine, and facilitatory electrotonic coupling effects indicate a unique mechanism of action for modafinil that may be exploited in development of treatment strategies for cocaine use disorders.

\section{FUNDING AND DISCLOSURE}

Support for this research was provided by funds from the National Institute on Drug Abuse-Intramural Research Program, NIH/ DHHS (Z1A DA000389 and Z1A DA000611). The authors declare no competing interests.

\section{ACKNOWLEDGEMENTS}

The authors thank J. Cao for providing the $( \pm)$ modafinil used in this study, synthesized in the Medicinal Chemistry Section, NIDA-IRP.

\section{AUTHOR CONTRIBUTIONS}

MM, TH, JLK, and GT designed the experiments. MM, TH, JDK, LEC, JPL, MAC, JCQ, CJJ, and GHB carried out the experiments. MM, TH, CJ, ZXX, AHN, JLK, and GT analyzed the data. AHN provided new agents and analytic tools. MM, TH, JDK, CJ, ZXX, AHN, JLK, and GT wrote the paper. All authors read and contributed to the final version of the paper.

\section{ADDITIONAL INFORMATION}

Supplementary Information accompanies this paper at (https://doi.org/10.1038/ s41386-020-0680-5).

Publisher's note Springer Nature remains neutral with regard to jurisdictional claims in published maps and institutional affiliations.

\section{REFERENCES}

1. Volkow ND, Fowler JS, Logan J, Alexoff D, Zhu W, Telang F, et al. Effects of modafinil on dopamine and dopamine transporters in the male human brain: clinical implications. Jama. 2009;301:1148-54.

2. Madras BK, Miller GM, Fischman AJ. The dopamine transporter and attentiondeficit/hyperactivity disorder. Biol Psychiatry. 2005;57:1397-409.

3. Kuhar MJ, Ritz MC, Boja JW. The dopamine hypothesis of the reinforcing properties of cocaine. Trends Neurosci. 1991;14:299-302.

4. Tanda G, Newman AH, Katz JL. Discovery of drugs to treat cocaine dependence: behavioral and neurochemical effects of atypical dopamine transport inhibitors. Adv Pharm. 2009:57:253-89.

5. Kohut SJ, Hiranita T, Hong SK, Ebbs AL, Tronci V, Green J, et al. Preference for distinct functional conformations of the dopamine transporter alters the relationship between subjective effects of cocaine and stimulation of mesolimbic dopamine. Biol Psychiatry. 2014;76:802-9.

6. Loland CJ, Mereu M, Okunola OM, Cao J, Prisinzano TE, Mazier S, et al. R-modafinil (armodafinil): a unique dopamine uptake inhibitor and potential medication for psychostimulant abuse. Biol Psychiatry. 2012;72:405-13.

7. Schmitt KC, Reith ME. The atypical stimulant and nootropic modafinil interacts with the dopamine transporter in a different manner than classical cocaine-like inhibitors. PLoS ONE. 2011;6:e25790.

8. Castells X, Casas M, Perez-Mana C, Roncero C, Vidal X, Capella D. Efficacy of psychostimulant drugs for cocaine dependence. Cochrane Database Syst Rev. 2010;2:CD007380.

9. Kalechstein AD, Mahoney JJ 3rd, Yoon JH, Bennett R. De la Garza R 2nd. Modafinil, but not escitalopram, improves working memory and sustained attention in long-term, high-dose cocaine users. Neuropharmacology. 2013;64:472-8.
10. Vosburg SK, Hart CL, Haney M, Rubin E, Foltin RW. Modafinil does not serve as a reinforcer in cocaine abusers. Drug Alcohol Depend. 2010;106:233-6.

11. Food and Drug Administration U. FDA Approved Labeling, PROVIGIL ${ }^{\otimes}$ (modafinil) Tablets. http://www.accessdata.fda.gov/drugsatfda_docs/label/2007/ 020717s020s013s018lbl.pdf.

12. Mereu M, Bonci A, Newman AH, Tanda G. The neurobiology of modafinil as an enhancer of cognitive performance and a potential treatment for substance use disorders. Psychopharmacology. 2013;229:415-34.

13. Garcia-Rill E, Heister DS, Ye M, Charlesworth A, Hayar A. Electrical coupling: novel mechanism for sleep-wake control. Sleep. 2007;30:1405-14.

14. Liu X, Petit JM, Ezan P, Gyger J, Magistretti P, Giaume C. The psychostimulant modafinil enhances gap junctional communication in cortical astrocytes. Neuropharmacology. 2013;75:533-8.

15. Duchene A, Perier M, Zhao Y, Liu X, Thomasson J, Chauveau F, et al. Impact of astroglial connexins on modafinil pharmacological properties. Sleep. 2016;39: 1283-92.

16. Beck P, Odle A, Wallace-Huitt T, Skinner RD, Garcia-Rill E. Modafinil increases arousal determined by P13 potential amplitude: an effect blocked by gap junction antagonists. Sleep. 2008;31:1647-54.

17. Brady KT, Gray KM, Tolliver BK. Cognitive enhancers in the treatment of substance use disorders: clinical evidence. Pharmacol Biochem Behav. 2011;99: 285-94.

18. Sofuoglu M, DeVito EE, Waters AJ, Carroll KM. Cognitive function as a transdiagnostic treatment target in stimulant use disorders. J Dual Diagn. 2016;12:90-106.

19. Sofuoglu M, Mooney M. Cholinergic functioning in stimulant addiction: implications for medications development. CNS Drugs 2009;23:939-52.

20. Valentino RJ, Volkow ND. Drugs, sleep, and the addicted brain. Neuropsychopharmacol. 2020;45:3-5.

21. Mahoney JJ, Jackson BJ, Kalechstein AD, De La Garza R, Chang LC, Newton TF. Acute modafinil exposure reduces daytime sleepiness in abstinent methamphetaminedependent volunteers. Int J Neuropsychopharmacol. 2012;15:1241-9.

22. Morgan PT, Angarita GA, Canavan S, Pittman B, Oberleitner L, Malison RT, et al. Modafinil and sleep architecture in an inpatient-outpatient treatment study of cocaine dependence. Drug Alcohol Depend. 2016;160:49-56.

23. Morgan PT, Pace-Schott E, Pittman B, Stickgold R, Malison RT. Normalizing effects of modafinil on sleep in chronic cocaine users. Am J Psychiatry. 2010;167: 331-40.

24. Partridge BJ, Bell SK, Lucke JC, Yeates S, Hall WD. Smart drugs "as common as coffee": media hype about neuroenhancement. PLoS ONE. 2011;6:e28416.

25. Santoni de Sio F, Faulmuller N, Vincent NA. How cognitive enhancement can change our duties. Front Syst Neurosci. 2014;8:131.

26. Di Chiara G, Tanda G, Bassareo V, Pontieri F, Acquas E, Fenu S, et al. Drug addiction as a disorder of associative learning. Role of nucleus accumbens shell/ extended amygdala dopamine. Ann NY Acad Sci. 1999;877:461-85.

27. Tanda G, Pontieri FE, Di Chiara G. Cannabinoid and heroin activation of mesolimbic dopamine transmission by a common mu1 opioid receptor mechanism. Science. 1997;276:2048-50.

28. Kokarovtseva L, Jaciw-Zurakiwsky T, Mendizabal Arbocco R, Frantseva MV, Perez Velazquez JL. Excitability and gap junction-mediated mechanisms in nucleus accumbens regulate self-stimulation reward in rats. Neuroscience. 2009;159: 1257-63.

29. Moore $H$, Grace AA. A role for electrotonic coupling in the striatum in the expression of dopamine receptor-mediated stereotypies. Neuropsychopharmacology. 2002;27:980-92.

30. Cao J, Prisinzano TE, Okunola OM, Kopajtic T, Shook M, Katz JL, et al. Structureactivity relationships at the monoamine transporters for a novel series of modafinil (2-[(diphenylmethyl)sulfinyl]acetamide) analogues. ACS Med Chem Lett. 2010:2:48-52.

31. Hiranita T, Kohut SJ, Soto PL, Tanda G, Kopajtic TA, Katz JL. Preclinical efficacy of $\mathrm{N}$-substituted benztropine analogs as antagonists of methamphetamine selfadministration in rats. J Pharmacol Exp Ther. 2014;348:174-91.

32. Paxinos G, Watson C. The rat brain in stereotaxic coordinates. IV ed. Sydney: Academic Press; 1998. P.

33. Tanda G, Kopajtic TA, Katz JL. Cocaine-like neurochemical effects of antihistaminic medications. J Neurochem. 2008;106:147-57.

34. Tanda G, Mereu M, Hiranita T, Quarterman JC, Coggiano M, Katz JL. Lack of specific involvement of (+)-naloxone and (+)-naltrexone on the reinforcing and neurochemical effects of cocaine and opioids. Neuropsychopharmacology. 2016:41:2772-81.

35. Onn SP, Grace AA. Amphetamine withdrawal alters bistable states and cellular coupling in rat prefrontal cortex and nucleus accumbens neurons recorded in vivo. J Neurosci. 2000;20:2332-45.

36. Dere E, Zlomuzica A. The role of gap junctions in the brain in health and disease. Neurosci Biobehav Rev. 2012;36:206-17. 
37. Gatley SJ, Volkow ND, Gifford AN, Fowler JS, Dewey SL, Ding YS, et al. Dopaminetransporter occupancy after intravenous doses of cocaine and methylphenidate in mice and humans. Psychopharmacology. 1999;146:93-100.

38. Volkow ND, Wang GJ, Fowler JS, Fischman M, Foltin R, Abumrad NN, et al. Methylphenidate and cocaine have a similar in vivo potency to block dopamine transporters in the human brain. Life Sci. 1999;65:PL7-12.

39. Krishnan R, Chary KV. A rare case modafinil dependence. J Pharmacol Pharmacother. 2015;6:49-50.

40. Hart CL, Haney M, Vosburg SK, Rubin E, Foltin RW. Smoked cocaine selfadministration is decreased by modafinil. Neuropsychopharmacology. 2008;33:761-8.

41. Kampman KM, Lynch KG, Pettinati HM, Spratt K, Wierzbicki MR, Dackis C, et al. A double blind, placebo controlled trial of modafinil for the treatment of cocaine dependence without co-morbid alcohol dependence. Drug Alcohol Depend. 2015;155:105-10.

42. O'Donnell P, Greene J, Pabello N, Lewis BL, Grace AA. Modulation of cell firing in the nucleus accumbens. Ann NY Acad Sci. 1999;877:157-75.

43. Keighron JD, Quarterman JC, Cao J, DeMarco EM, Coggiano MA, Gleaves A, et al. Effects of (R)-modafinil and modafinil analogues on dopamine dynamics assessed by voltammetry and microdialysis in the mouse nucleus accumbens shell. ACS Chem Neurosci. 2019;10:2012-21.
44. Mereu M, Chun LE, Prisinzano TE, Newman AH, Katz JL, Tanda G. The unique psychostimulant profile of (+/-)-modafinil: investigation of behavioral and neurochemical effects in mice. Eur J Neurosci. 2017;45:167-74.

45. Holtz NA, Lozama A, Prisinzano TE, Carroll ME. Reinstatement of methamphetamine seeking in male and female rats treated with modafinil and allopregnanolone. Drug Alcohol Depend. 2012;120:233-7.

46. Andersen ML, Kessler E, Murnane KS, McClung JC, Tufik S, Howell LL. Dopamine transporter-related effects of modafinil in rhesus monkeys. Psychopharmacology. 2010;210:439-48.

47. Bernardi RE, Lewis JR, Lattal KM, Berger SP. Modafinil reinstates a cocaine conditioned place preference following extinction in rats. Behav Brain Res. 2009;204:250-3.

48. Dean AC, Sevak RJ, Monterosso JR, Hellemann G, Sugar CA, London ED. Acute modafinil effects on attention and inhibitory control in methamphetamine-dependent humans. J Stud Alcohol Drugs. 2011;72: 943-53.

49. Ghahremani DG, Tabibnia G, Monterosso J, Hellemann G, Poldrack RA, London ED. Effect of modafinil on learning and task-related brain activity in methamphetamine-dependent and healthy individuals. Neuropsychopharmacology. 2011;36:950-9. 